\title{
Rheumatologists in Ecuador: Results of a Survey
}

\author{
Genessis Maldonado $\mathbb{D}$, ${ }^{1}$ Maria Intriago $\mathbb{D},^{2}$ Roberto Guerrero $\mathbb{D}{ }^{2}$ and Carlos Rios $\mathbb{D}^{2}$ \\ ${ }^{1}$ MacNeal Hospital, Internal Medicine Department, 3249 S Oak Park Ave, Berwyn, IL 60402, USA \\ ${ }^{2}$ Universidad Espiritu Santo, $2.5 \mathrm{Km}$ La Puntilla, Samborondón, Ecuador \\ Correspondence should be addressed to Genessis Maldonado; genesismaldonadovelez92@gmail.com
}

Received 16 April 2020; Revised 18 November 2020; Accepted 10 December 2020; Published 21 December 2020

Academic Editor: Naohiko Ueno

Copyright (C) 2020 Genessis Maldonado et al. This is an open access article distributed under the Creative Commons Attribution License, which permits unrestricted use, distribution, and reproduction in any medium, provided the original work is properly cited.

\begin{abstract}
Introduction. Currently, there are no records of the current status of rheumatologists in Ecuador. Objective. The purpose of this study is to get to know the current status of rheumatologists in Ecuador, focusing on education, working conditions, productivity, distribution of time between work activities, and job satisfaction. Materials and Methods. A digital survey was created using the Google Forms platform. It was distributed to all rheumatologist members of the Ecuadorian Society of Rheumatology. The data analysis was carried out using the statistical program SPSS v.23 ${ }^{\circledR}$. Results. A total of 64 surveys were received. The response rate was $86.48 \% .62 .5 \%$ were men and $37.5 \%$ women, with an average age of $40.76 \pm 9.18$. The main workplace was state/public hospital (56.3\%). The average working hours per week were $40.35 \pm 25.72$. Most rheumatologists in Ecuador (62.5\%) received their training abroad. $79.7 \%$ of rheumatologists earn less than $\$ 49,000$ annually. The mean retirement age was $66.51 \pm 6.7$, and $54.7 \%$ have a retirement plan. The average satisfaction of Ecuadorian rheumatologists was $5.4 \pm 1.33$ [0-7]; 17.2\% are very dissatisfied with their annual income. Conclusions. This is the first recorded data on the characteristics of rheumatologists in Ecuador. Most rheumatologists obtained their specialist degree abroad. In general, rheumatologists in Ecuador are satisfied with their clinical practice and dissatisfied with their annual income and job security.
\end{abstract}

\section{Introduction}

Rheumatology was recognized as a medical specialty in the $20^{\text {th }}$ century; doctors Bernard Comroe and Joseph Lee Hollander were the first to introduce the term "Rheumatologist" in 1940 [1]. In Ecuador, the Rheumatology Society (SER) was created in 1960, which is one of the oldest scientific societies in the country [2]. Currently, SER has 74 specialists and in recent years, there has been an increase in the participation of young rheumatologists [3]. Approximately $90 \%$ of all rheumatologists belong to the Ecuadorian Society of Rheumatology [3].

The latest census data obtained in 2010 by the National Institute of Statistics and Censuses (INEC) report that Ecuador has 16.62 million inhabitants [4], and according to data from the Ministry of Public Health, there are approximately 29,734 general practitioners, which represents a rate of 18 doctors for every 10,000 inhabitants [5].
Furthermore, national figures for 2011 report around 19,083 medical specialists [5].

Currently, there are research articles on the well-being of rheumatologists in the United States [6]; in general, rheumatologists reported being satisfied with their practice as specialists, and it was shown that there is an increase of $1.2 \%$ in rheumatologists [7]. Maldonado et al. recently reported the current status of rheumatologists in Latin America and showed that rheumatologists in the region are very satisfied with their clinical practice and workplace, yet they are dissatisfied with their annual income and job security [7].

Dejaco et al. compared public health models from various countries in the region and determined that 1-3 rheumatologists per 100,000 inhabitants are needed. In Ecuador, we cannot determine this figure because we do not have the total number of rheumatologists; however, 74 rheumatologists are part of the Ecuadorian Society of Rheumatology. 
Currently, we do not have information about the current status of rheumatologists in Ecuador. The purpose of this study is to get to know the current status of rheumatologists in Ecuador, focusing on education, working conditions, productivity, time distribution between work activities, and job satisfaction.

\section{Materials and Methods}

A digital survey was created using the Google Forms platform. It was distributed to all rheumatologist members of the Ecuadorian Society of Rheumatology. The data analysis was carried out using the statistical program SPSS v. $23^{\circledR}$.

The survey consisted of 45 questions that covered demographic data, comorbidities, clinical practice information, job satisfaction, and access to diagnostic techniques. Demographic variables included age, sex, marital status, number of children, race, country of birth, country of medical school graduation, and country in which their rheumatology fellowship was completed. The survey also asked about common comorbidities such as high blood pressure, diabetes mellitus, gastrointestinal, thyroid, autoimmune, and vascular diseases, gout, depression, and osteoarthritis.

Regarding clinical practice, the activities carried out in a work week, the number of weekly working hours, and the average annual income for the year 2017 were included. The survey also included questions about early access to an arthritis clinic, an infusion unit, X-rays, bone densitometry, and magnetic resonance imaging. Additionally, the survey asked if the participants had training in bone densitometry reading, ultrasound interpretation, and magnetic resonance imaging.

For job satisfaction, a visual analog scale graduated from 0 to 7 [8] was used. Six aspects of professional satisfaction were studied: practice satisfaction, job growth satisfaction, workplace satisfaction, annual income satisfaction, job security, and satisfaction with colleagues. The survey also asked about malpractice insurance, personal health insurance, and retirement plan.

2.1. Data Analysis. Duplicate responses were excluded, and the response rate obtained from the country was calculated using information provided by the Ecuadorian Society of Rheumatology secretariat regarding the number of rheumatologists as of October 2018.

The data were analyzed using the SPSS v23 statistical program. Frequencies, percentages, means, and standard deviation were calculated. The ANOVA test was used to analyze the differences between means, while the chi-square test was used for the categorical variables. Statistical significance was less than 0.05 .

\section{Results}

Sixty four surveys of rheumatologist members of the Ecuadorian Society of Rheumatology (SER) were received. The response rate was $86.48 \%$, and the demographic characteristics are described in Table 1. 70.3\%
TABle 1: Demographic characteristics.

\begin{tabular}{lcc}
\hline Parameters & $n(\%)$ & $p<0.05$ \\
\hline Female & $24(37.5)$ & 0.003 \\
Male & $40(62.5 \%)$ & 0.003 \\
Age & $40.76 \pm 9.18$ & \\
\hline Race & & \\
$\quad$ Mixed (mestizos) & $58(90.6)$ & 0.297 \\
$\quad$ White & $4(6.3)$ & \\
$\quad$ African American & $1(1.6)$ & \\
$\quad$ Indigenous & $1(1.6)$ & \\
\hline Marital status & & 0.01 \\
$\quad$ Married & $48(75)$ & \\
Single & $11(17.2)$ & 0.000 \\
$\quad$ Living together & $4(6.3)$ & \\
Divorced & $1(1.6)$ & \\
$\quad$ Number of children & $2(0-5)$ & \\
\hline
\end{tabular}

(45) are engaged in adult rheumatology, 6.3\% (4) are engaged in pediatric rheumatology, and $23.4 \%$ (15) practice internal medicine.

The main workplace was state/public hospital (56.3\%) (36), followed by private practice (26.6\%) (17), private hospital/clinic (10.9\%) (9), university hospital (3.1\%) (2), and nonprofit organization (3.1\%) (2) (Figure 1). The average working hours per week were $40.35 \pm 25.72$. No significant differences were found in the workplace according to $\operatorname{sex}(p=0.201)$.

Those who worked in a private hospital/clinic had a higher amount of working hours $(46.12 \pm 10.60)$ than rheumatologists in other workplaces such as state/public hospital $(39.91 \pm 21.60)$, private practice $(34.17 \pm 16.47)$, nonprofit organization $(33.00 \pm 10.30)$, and university hospitals $(26.00 \pm 9.79)(p=0.005)$.

Regarding the type of patients they serve, $31.3 \%$ (20) of the patients had private insurance, $26.6 \%$ (17)had government insurance, $17.2 \%$ (10)had labor insurance, $4.7 \%$ (3) had another type of insurance, and $20.3 \%$ (11) did not have medical insurance.

In relation to other activities, $14 \%$ were dedicated to administrative work, $36 \%$ did teaching, $14.1 \%$ did clinical research, and $3.1 \%$ did clinical trials. It was found in women that $4.2 \%$ did administrative work ( $p=0.078), 37.5 \%$ taught classes $(p=0.840)$, and $12.5 \%$ did clinical research $(p=0.781)$. Of the men, $20 \%$ did administrative work, 35\% did teaching, $15 \%$ did clinical research, and 5\% did clinical trials. There were no significant differences between men and women in relation to the activities performed.

$84.4 \%$ (54) do not have access to an early arthritis clinic, and $51.6 \%$ (33) have access to an infusion unit. Regarding access to diagnostic tools, $82.8 \%$ (53) have access to X-rays, $43.8 \%$ (28) have access to a densitometer, $46.9 \%$ (30) have access to ultrasound, and $35.9 \%$ (23) have access to magnetic resonance imaging. However, most rheumatologists work in collaboration with other medical centers.

Regarding training in the use of these diagnostic tools, $18.8 \%$ of rheumatologists have training in ultrasound, $73.4 \%$ in densitometric reading, and $32.8 \%$ in magnetic resonance imaging. Finally, $7.8 \%$ of rheumatologists are currently undergoing 


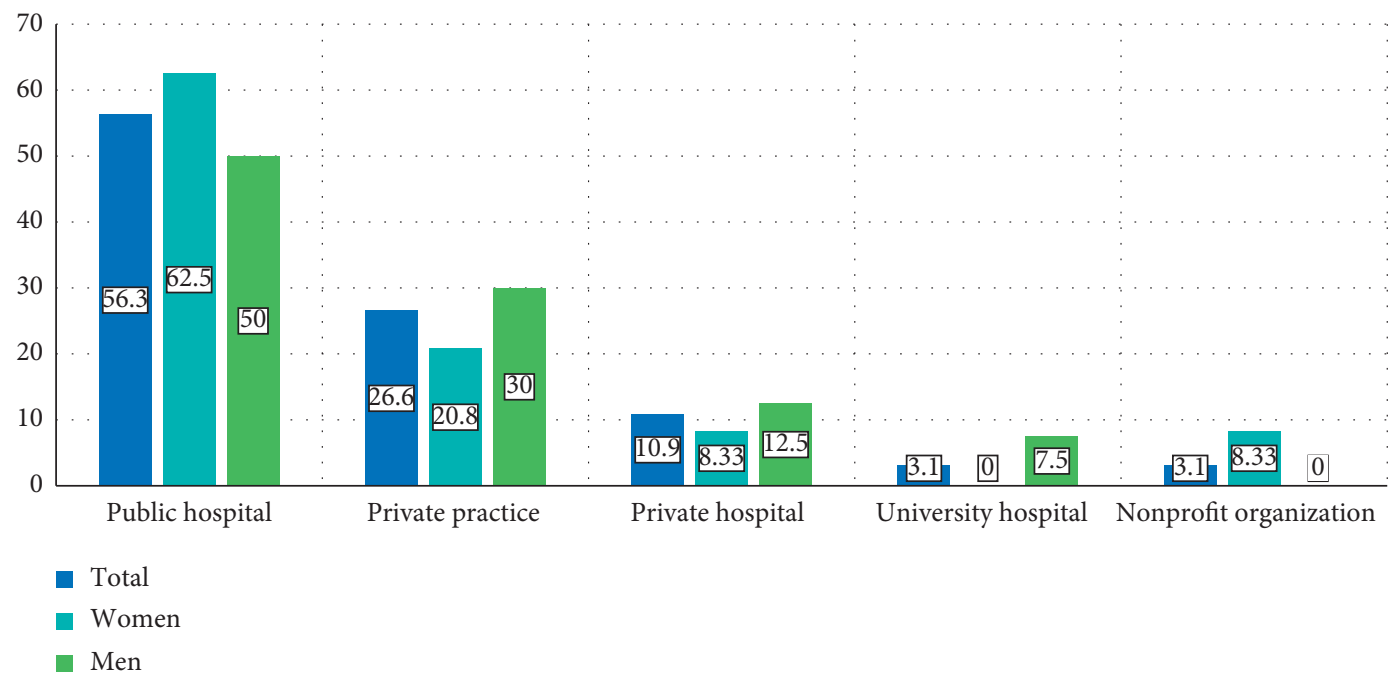

FIGURE 1: Main workplace of rheumatologists in Ecuador.

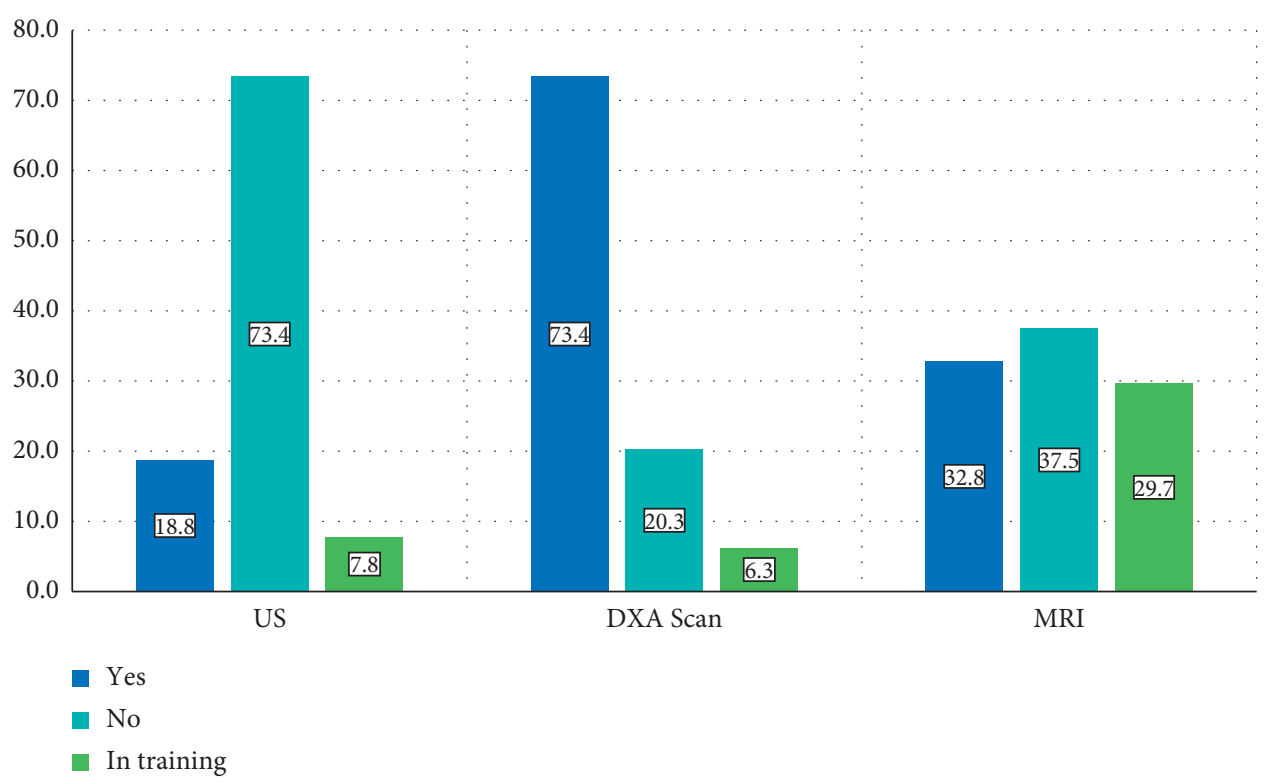

Figure 2: Training in the use of diagnostic tools.

training in ultrasound, $6.3 \%$ in densitometric reading, and $29.7 \%$ in magnetic resonance imaging (Figure 2).

In regard to medical school education, the majority graduated as medical doctors in Ecuador (95.3\%) (61). Regarding their postgraduate degree in rheumatology, 37.5\% did their training in Ecuador and $62.5 \%$ abroad, the majority in Argentina (20) as seen in Figure 3.

In relation to income, $26.6 \%$ have an annual income of less than \$ 19,$000 ; 23.4 \%$, \$ 20-29,000; $17.2 \%$, \$ 30-39,000; $12 \%$, \$ 40-49000; 7.8\%, \$ 50-99,000; 9.4\%, \$ 100-149,000; $1.6 \%, \$ 150-199,000$; and $1.6 \%, \$ 300-349,000$.

$79.7 \%$ of rheumatologists earn less than $\$ 49,000$ annually, while only $12.6 \%$ earn more than $\$ 100,000$. Men have more income than women; $70 \%$ of men have an annual income above $\$ 39,000$, compared to women where only $20.82 \%$ have an income of over $\$ 39,000$ (Figure 4).

Regarding comorbidities, $24 \%$ had at least one. Among the most common comorbidities in men, osteoarthritis was observed in $81 \%$, thyroid disease in $75 \%$, and hypertension in $69 \%$; while in the group of women, thyroid disease and osteoarthritis were evident in 29\%, 14\% had autoimmune diseases, and $7 \%$ had depression.

$32.8 \%$ (21) have malpractice insurance, and $87.5 \%$ (56) have medical insurance. The mean retirement age was $66.51 \pm 6.7$, and $54.7 \%$ (35) have a retirement plan.

$42.2 \%$ (27) of rheumatologists want a reduction in their working hours by $20 \%$, and $57.8 \%$ (37) want a reduction in hours of direct patient care. $34.4 \%$ do not want to change their working hours, and $37.5 \%$ (24) do not want changes in 


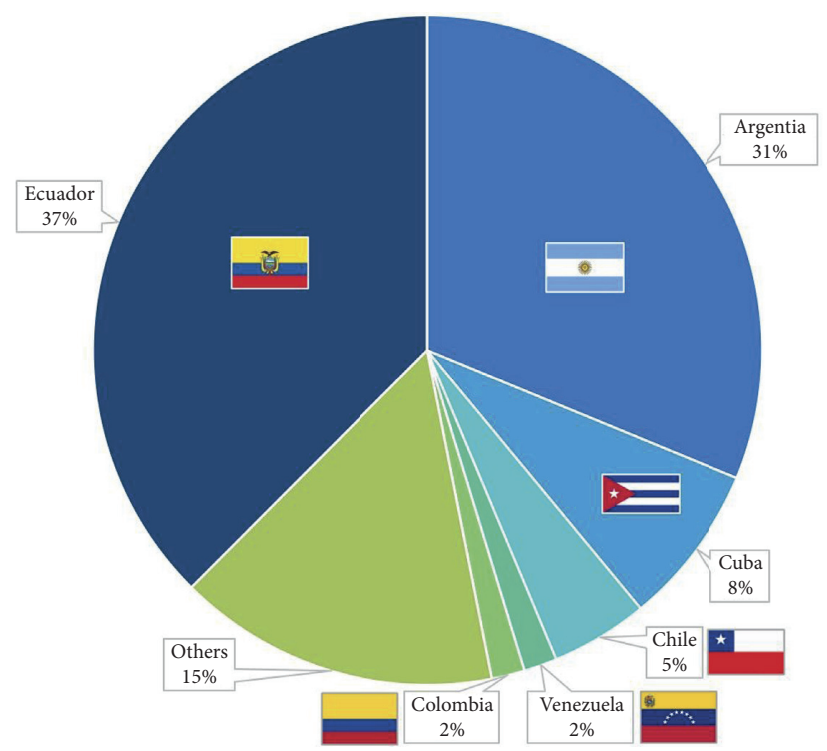

FIGURE 3: Countries in which rheumatology fellowship was obtained.

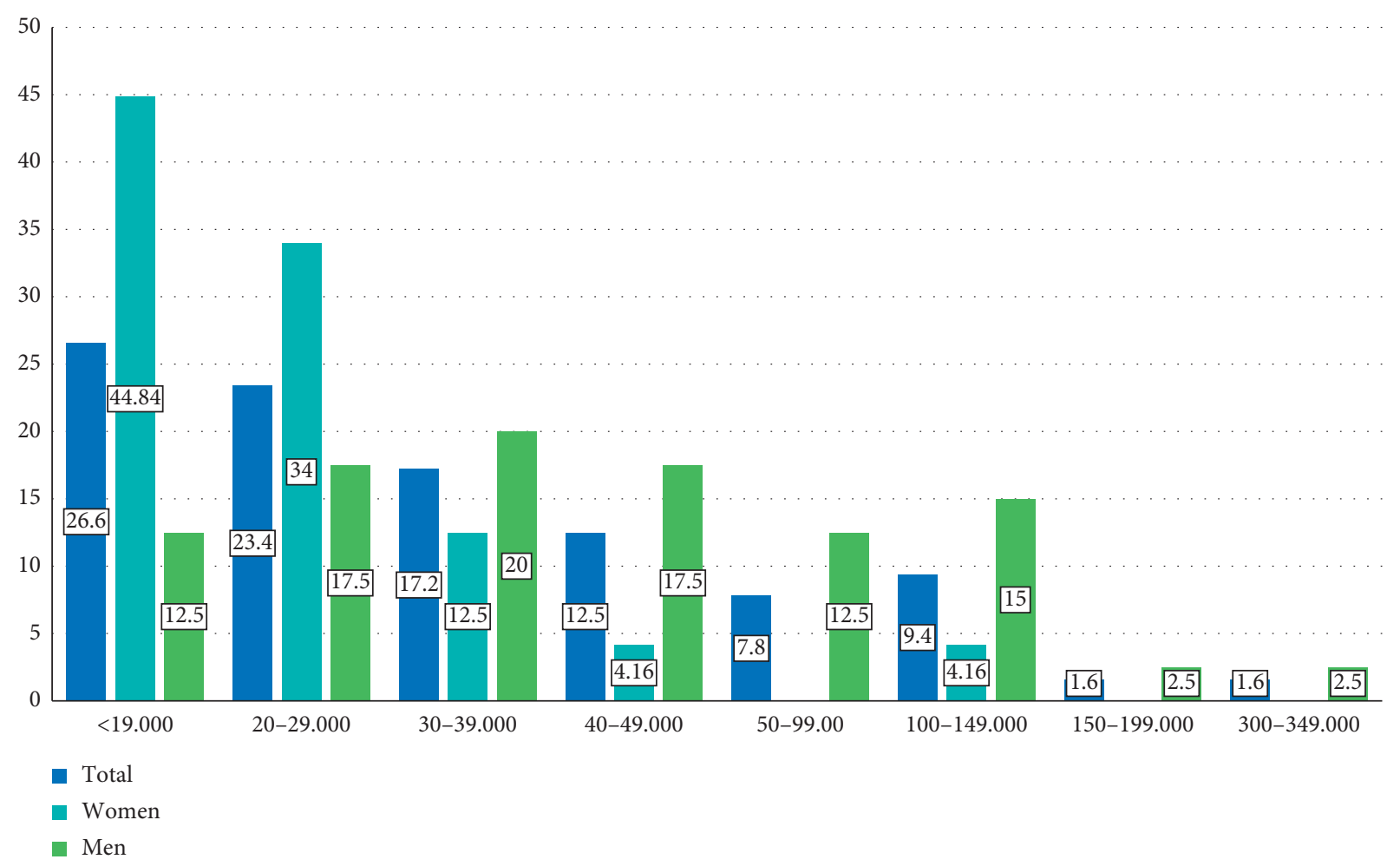

Figure 4: Annual income.

patient care hours. 3.2\% (2) would like to have an increase in working hours and direct care with patients (Figure 5).

The average satisfaction of Ecuadorian rheumatologists was $5.4 \pm 1.33$ [0-7]; $23.4 \%$ are very satisfied with their professional growth and $31.3 \%$ with their practice location; however, $17.2 \%$ are very dissatisfied with the annual income, $15.6 \%$ with job security, and $15.6 \%$ with their colleagues.
The degree of satisfaction was significantly higher in men in terms of general satisfaction $(5.7 \pm 1.1$ vs. $4.9 \pm 1.5$, $p=0.018)$, professional growth $(4.8 \pm 2.0$ vs. $3.7 \pm 2.2$, $p=0.041)$, location of practice $(5.2 \pm 1.9$ vs. $3.8 \pm 2.3$, $p=0.013)$, annual income $(4.5 \pm 1.7$ vs. $3.0 \pm 1.8, p=0.001)$, job security $(4.5 \pm 1.9$ vs. $3.3 \pm 2.1, p=0.019)$, and with colleagues $(4.8 \pm 1.7$ vs. $3.5 \pm 2.3, p=0.014)$. 


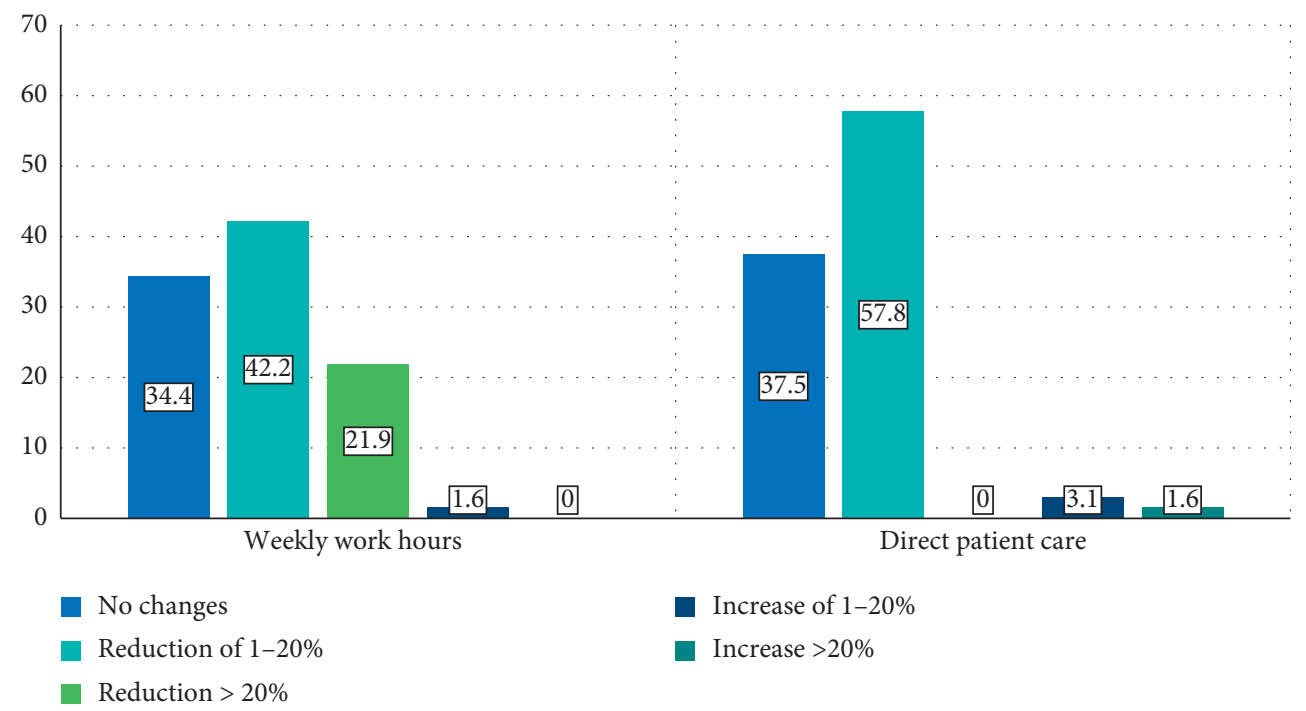

Figure 5: Desired changes in the clinical practice of Ecuadorian rheumatologists.

\section{Discussion}

The demographic characteristics of rheumatologists in Ecuador show that the majority are mestizos, similar to what was reported in the population census of the National Institute of Statistics and Censuses, which showed that $71.9 \%$ of the Ecuadorian population are mestizos [12].

In the present study, it was evident that the majority of Ecuadorian rheumatologists who work in public hospitals and private practices have access to infusion units and $\mathrm{X}$-rays. However, they do not have direct access to an early arthritis clinic, bone densitometry, magnetic resonance imaging, or ultrasound.

A similar study by Hogan and Bouchery [6] showed that $32 \%$ of US rheumatologists work in a private practice and $74 \%$ had access to infusion units, $64 \%$ to densitometry, $55 \%$ to X-rays, and $21 \%$ to an early arthritis clinic. These data are superior to the data presented in our study.

Likewise, in Canada, a study of rheumatologist found that $55 \%$ were dedicated to private practice and $32.6 \%$ in association with other physicians. The daily hours are mostly 9-10 working hours, and only $23.9 \%$ work 7 to 8 working hours a day [7], data similar to our average of 40 working hours per week. The Medscape Rheumatologist Compensation Report 2018 [8] described that 78\% of rheumatologists dedicated 30-45 hours a week to see patients, while $96 \%$ dedicated more than 5 hours a week to administrative activities.

Regarding academic training, most of them studied medicine in Ecuador, while more than half completed their rheumatology fellowship abroad, mainly in Argentina. According to a study by the Pan American Health Organization (PAHO) [10], within the countries of Latin South America, there are rheumatology specialty programs in Cuba, the Dominican Republic, Costa Rica, Paraguay, Uruguay, Argentina, Bolivia, Brazil, Chile, Colombia, and Peru. Currently, Ecuador does not offer a rheumatology fellowship training.
Migration in Ecuador is an evident phenomenon, and it is estimated that $7.3 \%$ of the country's households have been affected by migration in search of work or study, especially to the United States, where it is estimated that around 2.5 million Ecuadorians live, and Spain where about half a million live [13]. The migration of health personnel is also a serious problem due to the leakage of investigative capacity and the deficit of personnel that they create in the health system [13]. A study found that of the doctors graduated in 2001 in Ecuador, 13.4\% have left the country in search of specialization, the majority being men and from private universities [13].

Most rheumatologists in Ecuador receive an annual income of less than $\$ 30,000$, which is significantly less than that found in other studies. According to data from the Ecuadorian Ministry of Public Health, an Ecuadorian doctor receives $\$ 1,676$ to $\$ 2,967$ per month, which is equivalent to an average of $\$ 28,000$ per year [11]. In Hogan and Bouchery's study [3], only 9\% earned less than \$100K a year while in the Medscape Rheumatologist Compensation Report 2018, the annual income of rheumatologists in the United States was \$259K [14]. A study about doctors' compensation in different countries showed that the United States is the country with the best annual remuneration with $\$ 313 \mathrm{~K}$, well above Spain with \$ 63K, Brazil with $\$ 58 \mathrm{~K}$, and Mexico with $\$ 22 \mathrm{~K}$, showing that there is a large gap between the United States and Latin America [11]. From the region, it is estimated that Brazil and Chile have the highest salaries and Ecuador has an average salary between $\$ 10$ and 26K, while Cuba and Venezuela have the lowest salaries.

\section{Conclusion}

This is the first reported data of rheumatologists in Ecuador. $63 \%$ completed their rheumatology fellowship abroad. In general, they are satisfied with their clinical practice, but they are dissatisfied with their annual income and job security. 
We consider that this study will enhance the interest of rheumatology in Ecuadorian young medical doctors.

\section{Data Availability}

Data supporting this research article are available from the corresponding author upon request.

\section{Ethical Approval}

This study was approved by the Ethics and Teaching Committee of the Centro de Reumatología y Rehabilitación (CERER) (registration number: 004/2020; Folio 01: Book of Acts No. 1).

\section{Disclosure}

The authors are part of the rheumatology department of the Universidad Espiritu Santo.

\section{Conflicts of Interest}

The authors declare that they have no conflicts of interest.

\section{Authors' Contributions}

C. Rios and G. Maldonado were responsible for study conception and design. M. Intriago, R. Guerrero, G. Maldonado, and C. Rios were responsible for data acquisition. M. Intriago, G. Maldonado, and R. Guerrero conducted analysis and data interpretation. G. Maldonado, M. Intriago, and R. Guerrero wrote the manuscript draft. C. Rios provided critical revision.

\section{References}

[1] G. Pasero and P. Marson, "Hippocrates and rheumatology," Clinical and Experimental Rheumatology, vol. 22, no. 6, pp. 687-689, 2004.

[2] Sociedad Ecuatoriana De Reumatología, Sociedad Ecuatoriana De Reumatología: Estatuto Reformado y Codificado, Sociedad Ecuatoriana De Reumatología, Guayaquil, Ecuador, 2011, http://www.serecuador.com.ec/wp-content/uploads/2016/04/ ESTATUTOS-SER.pdf.

[3] Colegio De Médicos De Pichincha, Entrevista Al Dr. Mario Moreno, Presidente De La Sociedad Ecuatoriana De Reumatología Comunicados, Colegio De Médicos De Pichincha, Quito, Ecuador, 2018, https://colegiomedicodepichincha.org/2018/12/27/la-unionde-las-sociedades-cientificas-nos-permitira-trabajar-mejor-queantes-entrevista-al-dr-mario-moreno-presidente-de-la-sociedadecuatoriana-de-reumatologia/.

[4] Instituto Nacional De Estadísticas y Censos, Resultados Del Censo 2010, Instituto Nacional De Estadísticas y Censos, Quito, Ecuador, 2010, http://www.ecuadorencifras.gob.ec/ resultados/.

[5] Instituto Nacional De Estadísticas y Censos, Anuario de Recursos y Actividades de Salud, Instituto Nacional De Estadísticas y Censos, Quito, Ecuador, 2011.

[6] P. Hogan and E. Bouchery, Workforce Study of Rheumatologists: Final Report, Lewin Group, Falls Church, VA, USA, 2006, https://www.rheumatology.org/Portals/0/Files/Lewin Study Overview.pdf.
[7] G. Maldonado, E. Soriano, L. Moreno, and C. Rios, "LARS study: Latin American rheumatologist survey," Journal of Clinical Rheumatology, vol. 25, no. 3S, p. S195, 2019.

[8] J. Brill, "Likert sacale," in Encyclopenia of Survey Research Methods, P. J. Lavrakas, Ed., SAGE Publications, Inc., London, UK, 2nd edition, 2008.

[9] C. L. Deal, R. Hooker, T. Harrington et al., "The United States rheumatology workforce: supply and demand, 2005-2025," Arthritis \& Rheumatology, vol. 56, no. 3, pp. 722-729, 2007.

[10] Organización Panamericana De La Salud, Residencias Médicas En América Latina, Organización Panamericana De La Salud, Washington, DC, USA, 2011, https://www.paho.org/hq/ dmdocuments/2012/HRS-SerieAPSNo5-Residencias.pdf.

[11] Ministerio De Salud Pública Del Ecuador, MSP Conmemora el Día Del Médico Ecuatoriano, Reconocido Actor De La Transformación De La Salud, Ministerio De Salud Pública Del Ecuador, Quito, Ecuador, 2017.

[12] B. Villacís and D. Carrillo: País atrevido: la nueva cara sociodemográfica del Ecuador, 2012, https://www.ecuad orencifras.gob.ec/wp-content/descargas/Libros/Economia/ Nuevacarademograficadeecuador.pdf.

[13] Organización Panamericana De La Salud, Aproximaciones a La migración Del Talento Humano En Salud En Ecuador, Organización Panamericana De La Salud, Washington, DC, USA, 2007.

[14] L. Kane, Medscape Rheumatologist Compensation Report 2019, Medscape Inc., New York, NY, USA, 2019. 